\title{
MODERN CONDITION OF MATURITY OF INTERCULTURAL COMPETENCE OF MASTERS OF MILITARY MANAGEMENT: RESULTS OF QUESTIONING
}

\author{
Valeriia Skrypnikova \\ Postgraduate Student, Ivan Cherniakhovskyi National Defence University of Ukraine, Ukraine \\ e-mail: wellsvo087@ukr.net, orcid.org/0000-0002-0056-7299
}

\section{Summary}

The article contains the analysis of questioning concerning attitude to necessity of development of intercultural competence of future Masters of military management (MMM), importance of intercultural awareness, study of the level of intercultural awareness of military officers of the Armed Forces of Ukraine (by self-assessment). There was defined the level of orientation within the terms (intercultural communication, intercultural competence, ethnocentrism, multicultural state), understanding of the reasons of conflicts between the representatives of different cultures. We have studied which characteristics are preferred by future Masters of military management in a specialist with a developed intercultural competence.

The purpose of the article is to define topicality of necessity to develop intercultural competence of future masters of military management in their professional training, to find out the general level of understanding of main principles and fundamentals of intercultural communication in military sphere for outlining the further direction of the research.

For the aim of further research, we have designed the survey form and conducted the questionnaire at the beginning of findings stage of pedagogical experiment, which contained the range of tasks as follows: 1) to define the level of importance of possession of intercultural awareness among future MMM; 2) to study the level of understanding by the future Masters of military management of intercultural values, intercultural features, existing intercultural differences; if tolerance is important in intercultural interaction and what are the ways of its achievement; 3) to define what is the reason of intercultural conflicts, what obstacles arise and prohibit efficiency of intercultural communication; 4) to sort out what assessment criteria are important for a specialist possessing intercultural competence in professional activity; 5) to analyse the results.

Keywords: intercultural competence, intercultural dialog, awareness, intercultural awareness, professional training, questioning results, multiculturedness, technologies of combined studying, case study method.

\section{DOI: https://doi.org/10.23856/4416}

\section{Introduction}

Modern challenges faced by our state and European Union, as well as NATO countries concerning providing a proper management and saving of cultural variety constantly need the search of not only new modern approaches to solutions of intercultural dialogue issues, but correspondingly the development of intercultural competence of each participant of this process, that is discussed in the White Paper on Intercultural Dialogue of Council of Europe (White Paper, 2010:44) approved on May 7, 2008 in Strasbourg by the Council of Europe Ministers of Foreign Affairs at their 118th Ministerial Session. The White Paper contains special 
requirements to education, updating of its goals, content and forms that corresponds to requirements of Bologna process and National Doctrine of Education Development in Ukraine in XXI century (National Doctrine, 2001:21).

Activity of Ukraine on the international stage is determined by globalisation processes that influence communication peculiarities. That is why AF of Ukraine concentrate their attention on possibility to communicate in a language of foreign business partners, and at the same time the lack of knowledge of following kind arises: culturological, national-and-cultural, religious features of strategical partners, that makes an effective dialogue impossible.

\section{Methods and research situation}

To define the attitude of future Masters of military management to necessity of development of their intercultural competence we have conducted the survey. The survey had been conducted in the second half of 2020 under the auspices of Ivan Cherniakhovskyi National Defence University of Ukraine (city of Kyiv). 124 persons participated in the survey.

Designing the survey we have used several variants of questions composition, both free-answer questions and closed-end questions. The survey is anonymous. Questions of the survey are interrelated and partially cover each other in their content, which enables to verify the accuracy of the answers, they have a clarifying function. The survey was composed of two parts and nineteen questions; the first part contains five questions.

A part of questions required answers "Yes", "No", "I don't know". Another part of questions has a 10-points scale where the respondents had to select their level of intercultural awareness maturity ( 1 corresponds to the lowest one, 10 - to the highest one). Another part of questions contained ready variants of answers and needed choosing a needed one; in some of them it was possible to choose two and more answers. Free-answer questions required more deep knowledge and intercultural awareness, opportunity of creative approach in the process of these questions answering was given.

\section{Discussion of the results of empirical research}

Modern professional training of Ukrainian officer of 21 century within the framework of higher military education includes culturological, linguistic, ethical, social-and-communicative, psychological and applied professional dominant of officer's character education. As a result we believe that the scientific task of the modern time is development of students' (cadets') intercultural competence, ability and readiness to efficient participation in the process of intercultural dialogue.

Theoretical analysis of European regulations and treaties dealing with facilitation of intercultural dialogue and provision of efficient intercultural interaction shows that modern number-one-demand is possession of intercultural competence (hereinafter - IC). In the times of the world globalization and peoples' and cultures' rapprochement, conducting efficient intercultural dialogue, knowledge of intercultural features, and differences gain priority for future Masters of military management; issues of multicultural education and intercultural awareness are also topical. As a result a question arises: is there paid a due attention to the development of intercultural competence in the Armed Forces of Ukraine? In the state that actively participates in the arrangements of international military cooperation, joint international studies and trainings, conferences and seminars not only within Ukraine but also abroad, too much attention is paid to learning English and unfortunately the development of the very intercultural competence of future Masters of military management lacks attention. 
The analysis of the questionnaire enabled us to find answers to a range of important questions, and to solve current tasks we face. The results of the survey emphasise on the importance of possession by Masters of military management of intercultural awareness at the high level for the efficient professional activity, and indicate the topicality of the issue which is already studied not from the theoretical point of view, but from the practical one. Mentioned results will positively influence on the development of the educational course on the basis of intercultural communication, as well as its implementation to the program of professional training of future Masters of military management. We shall note that $(91,1) \%$ of respondents underlined the importance of intercultural awareness in their professional activity, and $(4,45) \%$ of respondents answered that it is not important for them and they did not decide yet on the necessity of intercultural skills equally. I.e. the major part of future Masters of military management feels the need in getting correspondent knowledge and development of skills in intercultural communication.

As to the definition of the level of intercultural competence maturity (self-assessment), only $(3,2) \%$ of future MMM admitted their level to be too low, $(65,3) \%$ defined their level as average, and $(31,4) \%$ noted the high level; nevertheless I'd like to mention that this is a simple survey without examination of respondents' psychological, cognitive, affective components, though it is planned for the further research. Most of respondents consider their level average and high, but future Masters of military management strive for improvement, which is witnessed by the survey showings. Answers to the question "Do you try to increase your level of intercultural awareness, and if yes, how?" revealed motivation component in future MMM basing on presence of certain motivation, value-orientedness, professional focus and desire for self-realisation, as far as efficiency of training or specialist's actions includes not only the defined skills and abilities, but they are multiplied and improved thanks to correspondent value-and-conceptual orientation (Tatur, 2004). Motivation to deepen intercultural knowledge, proficiency and skills development, ability to respond adequately and quickly, prevent and avoid conflicts, direction on professional and effective dialogue with the representatives of other cultures - all these define the person's commitment to the process of acquiring and developing intercultural competence on the high level.

Methods and means of self-improvement mentioned in the answers by future MMM are interesting today for getting knowledge in intercultural communication, that gives some ground for development of educational course involving innovative, interactive technologies.

The question "Do you try to increase your level of intercultural awareness, and if yes, how?" Gave an option to select several answers: The most respondents $(64,52) \%$ have chosen the method of "analysis of intercultural activity of well-known figures and adopt their experience"; $(41,94) \%$ of respondents "read special literature"; only $(8,87) \%$ "participate in training courses and seminars", and $(48,39) \%$ "reflexively estimate interaction with colleagues". We would mention that the amount of MMM who visit training courses is very small, and analysis of activity and reading of special literature is not enough for getting and deepening cognitive component, practical experience and improvement of skills on intercultural communication, as well as reflecting and analysing ones interaction. The process of intercultural communication engage lots of factors: Communicative (language, context, communication style, non-verbal behaviour); psychological (perception, evaluation, attribution, stereotypization, identification, empathy, reflection); cultural (norms, values, basic features, experience as the basis for psychological processes of communication) (Novitskaya, 2008).

We have analysed that $(57,26) \%$ of respondents estimate the level of intercultural awareness of military servicemen in the Armed Forces of Ukraine as an average, $(38,71) \%$ of respondents admitted it to be too low and only $(4,03) \%$ of respondents consider the level to be high. 
Nevertheless, at the same time $(51,61) \%$ of respondents reckon that the level of attention to the development of intercultural competence in higher military educational institutions is high, and $(29,84) \%$ state that this level is low, while $(18,55) \%$ gave no answer to this question. We conclude that military servicemen are in need of intercultural competence development and its improvement; though the level of attention to intercultural competence is high, the level of its development turned to be insufficient.

Analysis of answers of the second block of questions contains sub-items that allow to deeper define the level of understanding by future MMM of the concept of intercultural competence; almost all the respondents have a clue of its definition, yet having the access to the Internet. Looking through the results, we saw that the definition of the concept "intercultural competence" was given with the help of Internet-resources, as the answers have monotypic repeated segments. We came to this conclusion analysing the answers about definition of "intercultural communication" concept. Nevertheless, we shall note that $(86,29) \%$ of respondents believe that Ukraine is a multicultural state, $(10,48) \%$ think it is not multicultural, and only $(3,23) \%$ failed to answer this question. Surely, we conclude that the majority of respondents understand the meaning of "multicultural" concept.

The survey showed what turned to be main obstacles in the process of intercultural communication. According to the analysis, the main obstacle is thought to be "lack of knowledge and unawareness on culture features" (prejudices, customs, traditions, values, perception of space and time) - (57)\%, "inability to communicate in a language of a strategical partner as an obstacle" that hinders free and effective communication, takes the second place in our survey - (38)\%, "unawareness of religion, history, political structure of the partner state", as well as "lack of tolerance, not knowing how to behave in a company of the representative of other culture" gained (24)\% each. It shall be also noted that apperceptive features - "peculiarities of perception and dependence of perception from previous experience" of a personality is a substantial obstacle too $-(10) \%$ of respondents (pic. 1) though.

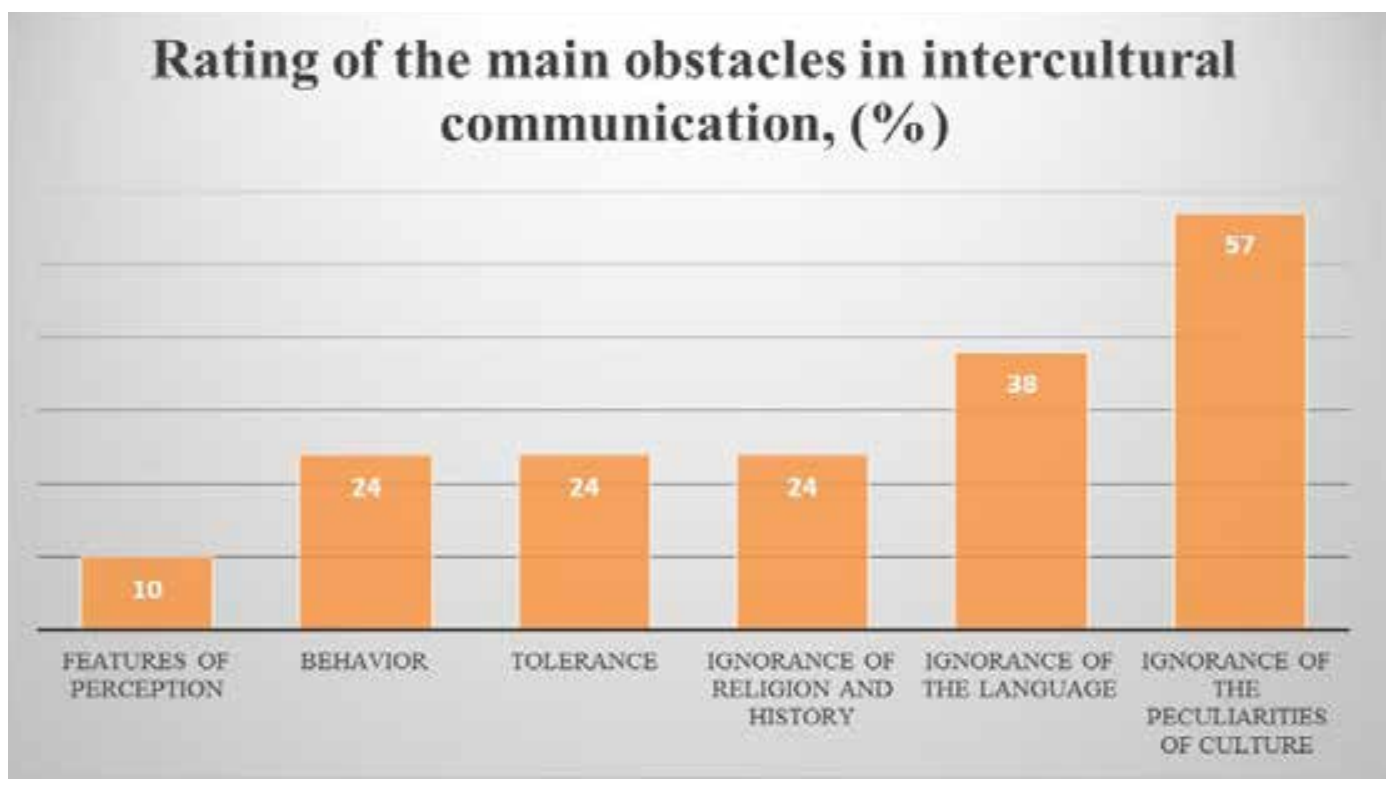

Pic. 1. Rating of the main obstacles in intercultural communication 
Erin Meyer - a modern researcher in the sphere of intercultural communication - believes that "consideration of individual differences is important, but only with regard to cultural origin, that is why we shall admit the weight of cultural differences and respect them, the first and the second are both important" (Meyer, 2014) and finally "lack of information on the basis and peculiar features of intercultural communication" is a sufficient obstacle $-(5) \%$.

Herewith, respondent do not consider inability to communicate in a language of a representative of another culture to be a reason of conflicts, the first place takes namely "unawareness, not understanding the differences and peculiarities of a culture, not knowing the principles of conduct" - (72)\%; "no tolerant attitude to a representative of another culture and divergence of mindset, as well as "differences in religion and political preferences" were chosen by (25)\% of respondents each, and only (10)\% of respondents consider "ignorance of the language" to be the reason of conflicts (pic. 2).

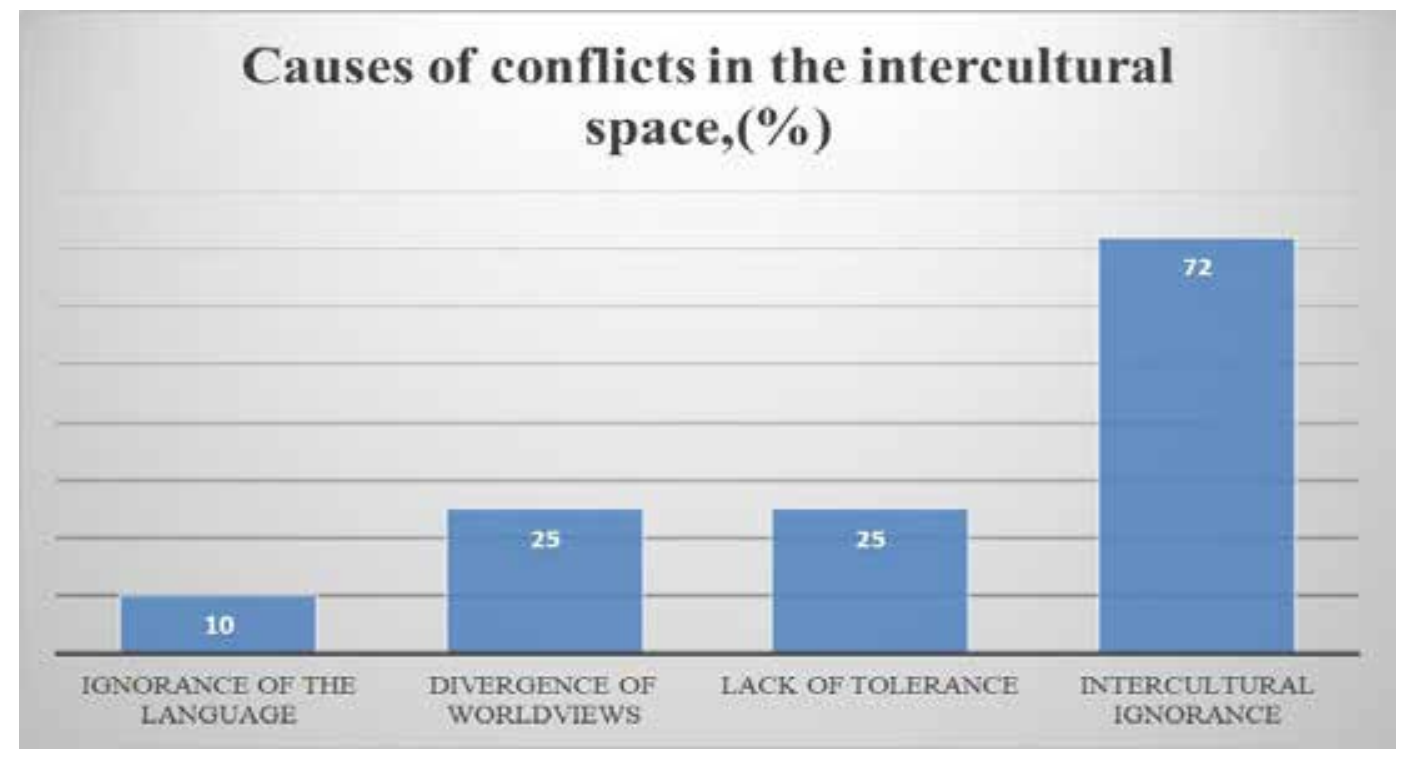

\section{Pic. 2. Causes of conflicts in the intercultural space}

Understanding of the fact that command of language itself is not enough is underlined by the most of scientists within this issue; they define the speech component as "an ability to render specific for certain culture signals of conversation participants' readiness to start intercultural conversation or, in contrary, unwillingness to communicate... Ability to define the proportion of speaking and listening depending on situation... Ability to express one's opinion adequately and to understand the opinion of the partner of conversation... Ability to steer the conversation on the right course..." etc. (Leontovych, 2003: 53,54). Individual question on the command of language only and if it is enough for successful intercultural communication revealed, that $(95,16) \%$ of respondents answered "no, command of language only is not enough for successful intercultural communication", and only $(4,03) \%$ of respondents think that command of language only will be enough, herewith $(0,81) \%$ did not manage to answer. At the same time, $(70,97) \%$ admit that "respect to values" of other people is not as strong for us as to our personal values. In our previous researches we have mentioned, that the complete integrated 
body of knowledge (sociocultural, linguistic, culturological, professional ones, knowledge of peculiar features, traditions, and behaviour of the partners), skills (of verbal and non-verbal communication, culturally-specific abilities and soft skills) and value orientations make the essence and the content of intercultural competence (Skrypnikova, 2020).

So, $(95,97) \%$ of future MMM mentioned that knowledge on intercultural differences is necessary for professional activity, and this again highlights the topicality of the issue under research. Also $(91,94) \%$ of respondents believe that tolerance to differences between cultures as a personal quality may be developed with the help of awareness of this cultures, as far as the divergence of relations, values and behaviour of people is culturally-based. Each personality forms own system of opinions and beliefs, in other words it has a certain range of cultural filters, through which we percept life. It is wrong to judge about other cultures from the viewpoint of our one, and $(96,77) \%$ of respondents agree with this, while $(3,23) \%$ did not manage to pick the answer. $(73,39) \%$ of respondents see the connection between the multicultural society and intercultural communication, $(5,65) \%$ do not think that this concepts are somehow related, and $(20,97) \%$ failed to answer the question. Analysis of the answers concerning ethnocentrism risks showed, that (55)\% of respondents "can not answer" what are the risks, (30)\% chosen such a dangerous aspect as "considering one's own culture to be above other cultures", (15)\% admitted, that there is a risk of "conflicts" in case of ethnocentrism, and only (9)\% of respondents had chosen the category of risks "nationalism, terrorism, chauvinism etc."; it is worth reminding that these questions allowed several answers.

Basing on the previous theoretical analysis of the definition of the sense of "intercultural competence" concept, we have defined that intercultural competence of future Master of military management is a dynamic, integral, complex, professionally-personal, able for self-improvement formation, that contains cumulative knowledge on culture and its peculiar features (both one's own and other representatives'), ability to apply practically the acquired knowledge, skills and experience in order to solve the tasks of intercultural communication and self-realization of future Master of military management in the process of interaction with the representatives of other cultures basing on creative and flexible approach, tolerance and sense of differences of other cultures (Skrypnikova, 2020). Taking into consideration the results of earlier studies, we have defined a number of the main criteria, which show the development of intercultural competence: culturological and speech knowledge and skills (command of language of other culture representative, values, differences from the culture of own country, wide reading, erudition, curiosity, deepening of one's own culture-related knowledge, ability to take an adequate view of semiotic meanings and figures of speech of other culture), that was separated into a cognitive component (cognitive component of an affective-cognitive constituent) of the author's model; the next criterion is a developed tolerance - no prejudice, tactfulness, avoidance of stereotypic thinking (affective component of affective-cognitive constituent); sociability - ability to create and maintain the atmosphere of trust, to avoid conflicts, to use non-verbal behaviour in concordance with the culture of a conversation partner, communication means, readiness and willingness to contact with the representatives of the countries of the world (personal component); self-reflection - ability to realize one's own behaviour, actions, to admit mistakes - refer to personal component; personal motivation - professional strivings, internality in the sphere of professional achievements, professional interests and values, life goals (personal component); ability to do an improvisation - ability of considering objective and subjective factors, external circumstances while choosing the strategies of behaviour, spontaneous behaviour, ability to apply available communicative experience (communicative-and-activity component) (Skrypnikova, 2021). 
Finally, to sort out what are the main characteristics of military specialists with the high level of intercultural competence, we have analysed and formed a "rating" of the most important qualities. Results of the analysis showed us, that $(98,07) \%$ underline the importance of "command of language of other culture representative", it means that language is an important instrument of an intercultural communication. The next of the mentioned criteria in the rating is the knowledge on "peculiar features of a culture" (one's own and representative's one) $(96,77) \%$. The third place of rating took "tolerance" and "ability to prevent conflicts" (improvisation) - $(93,55) \%$ each. The ability to apply the experience of intercultural communication, namely "Communicative skills" received $(88,71) \%$ of respondents' votes. There were also mentioned such important features for the professional in intercultural communication, as knowledge of "values of partner's culture", ability to "avoid stereotypical thinking", "tactfulness", "openness for knowledge replenishment", "readiness for intercultural competence", possession of such psychological features of the person, like "empathy", "flexible thinking", "critical thinking" (pic. 3).

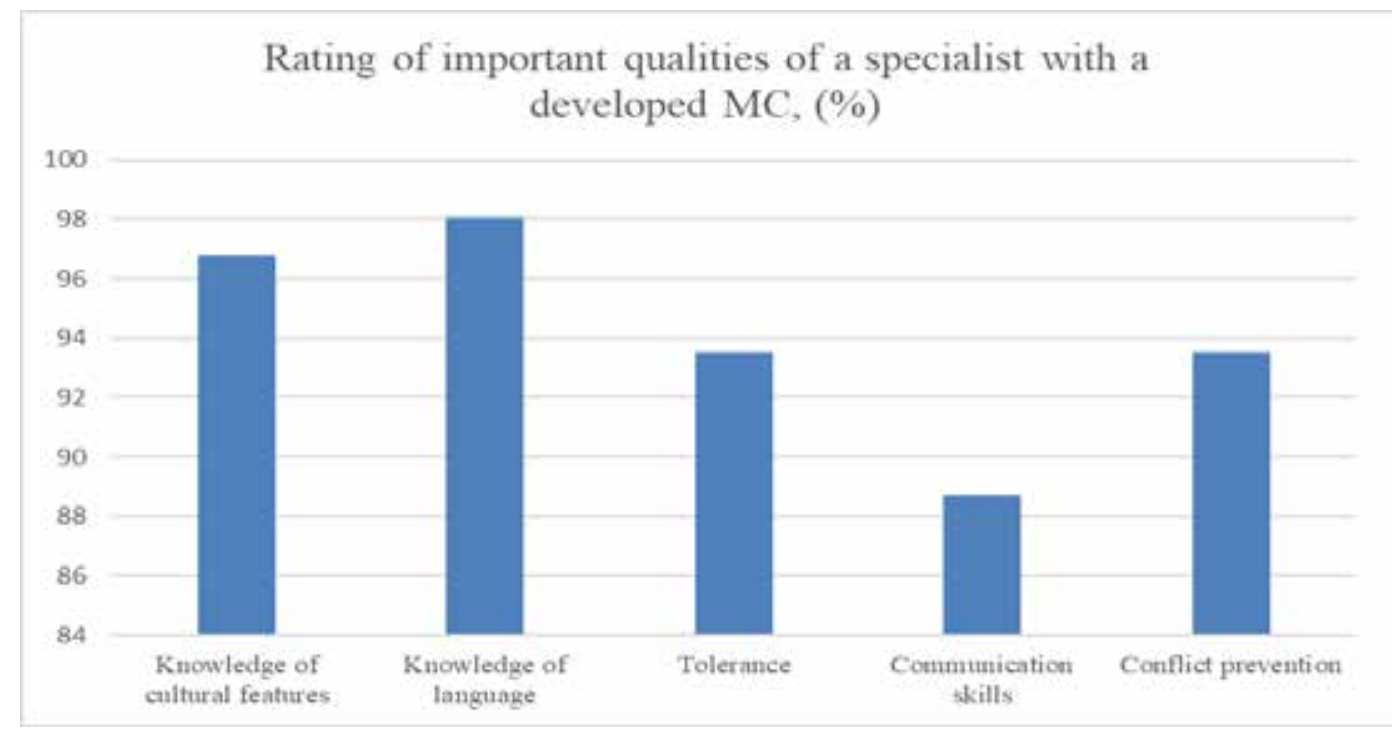

Pic. 3. Rating of important qualities of a specialist with a developed MC

\section{Conclusions}

Summarizing the research, we may make the following conclusions:

1. With the background of constant development of international contacts, international military cooperation, reformation of European and world educational orientation of Ukraine, it stays topical to achieve educational goals in training military specialists with the new type of thinking, able to act professionally, efficiently, creatively, applying all the potential of intercultural competence.

2. Analysis of the questionnaire results enables us to conclude that the issue of studying peculiarities of intercultural communication is important for the major part of students $(91,1 \%)$. The latter are interested in the development of intercultural competence and acknowledge the need in increase of their intercultural awareness level and effective intercultural communication. 
Analysis of the results witnesses that the reasons of conflicts are the obstacles in the intercultural communication, such as not knowing and not understanding the language, no tolerance, intercultural unawareness, behaviour, peculiarities of personal perception etc.

3. Professional training of future Masters of military management who are able to perform efficiently the tasks in complicated environment of international activity, shall be directed to the development of competencies containing getting soft skills. Taking into consideration the received results, we see fit for the development of intercultural competence, to recommend including to the content of educational process of HMEI educational programs, special training courses etc., the realization of which may be realized by implementation of modern innovative, interactive technologies involving the methods of active training. An ambitious direction of further research of the issue of development of intercultural competence of future Masters of military management in their professional training is studying current condition of their soft skills maturity.

\section{References}

Leontovych O. A. (2003) Rossyia y SShA. Vvedenye v mezhkulturnuiu kommunykatsyiu [Russia and the United States. Introduction to intercultural communication]. Volhohrad. [in Russian]

Meyer E. (2014) The culture map. NY: Public affairs. [in English]

National doctrine of education development of Ukraine in the XXI century (2001) Kyiv: School World. [in Ukrainian]

Novitskaya A.V. (2008) Formirovanie mezhkulturnoy kompetentsii v razlichnyih vidah mezhkulturnyih kontaktov [Formation of intercultural competence in various types of intercultural contacts] Ser. Humanities. № 6 [in Russian].

Skrypnikova V. (2020) Poniattia mizhkulturna kompetentnist: sutnist ta zmist [Concept Intercultural Competence: essence and content]. Naukovyi visnyk Mukachivskoho derzhavnoho universytetu [Scientific Bulletin of Mukachevo State University. Series Pedagogy Psychology] Retrieved from: https://www.idrinstitute.org/resources/a-developmental-approach-to-training-for-intercultural-sensitivity/] 1(11), 210-215 [in Ukrainian].

Skrypnikova V. (2021) Model rozvytku mizhkulturnoi kompetentnosti maibutnikh mahistriv viiskovoho upravlinnia u profesiinii pidhotovtsi [The model of development of intercultural competence of future military management masters in professional training] Zbirnyk naukovykh prats pedahohichni nauky ministerstvo osvity i nauky Ukrainy Khersonskyi derzhavnyi universytet [Collection of research papers "pedagogical sciences»] 94(2021), 120-129 [in Ukrainian].

Tatur Yu.G. (2004) Kompetentnostnyiy podhod v opisanii rezultatov i proektirovanii standartov vyisshego professionalnogo obrazovaniya [Competence approach in describing results and designing standards of higher professional education]. Moscow: Proceedings of the methodological seminar. [in Russian]

White Paper on Intercultural Dialogue "Living Together in Equality and Dignity" (2010). Kyiv: Oranta. [in Ukrainian] 